\title{
Formação continuada de professores
}

\author{
em ambientes virtuais: uma avaliação
}

Continuing teacher training in virtual environments

\author{
Jéssica Bell'aver ${ }^{1}$ \\ jehbellaver@gmail.com \\ David da Silva Pereira ${ }^{2}$ \\ davidpereira@utfpr.edu.br \\ Alessandra Dutra, ${ }^{3}$ \\ alessandradutra@utfpr.edu.br
}

\section{Resumo}

Este trabalho objetivou investigar as propostas de formação continuada para professores, por via de ambientes virtuais, e a sua identificação e aceitação por parte deles. A importância dessa questão está relacionada à grande facilidade de acesso à tecnologia, que hoje impulsiona várias instituições a fazerem uso dela na oferta de formação a professores. Para tanto, a pesquisa por meio da aplicação de questionários foi empregada em uma escola municipal de uma cidade do o este do Paraná. Espera-se oferecer uma contribuição para o campo educacional, mais especificamente à área de formação docente, apresentando elementos para uma reflexão crítica a respeito das propostas de formação continuada que perpassam as novas tecnologias.

Palavras-chave: Formação continuada, Novas tecnologias, Ambientes virtuais, Formação docente, Educação a distância

\begin{abstract}
This work aimed to investigate continuing teacher training proposals through virtual environments, and its acceptation and self-identifying by the teachers. The importance of this issue is due to the easier access to technology that nowadays stimulates many institutions to use and offer this kind of tools to teacher trainings through virtual platforms. Thus, we carried out a research using questionnaires applied in a public school of a city in the west of Parana state. This study hopes to offer a contribution to the educational field, more specifically to the area of teacher training, in an attempt to provide elements for a critical thought on the proposals for continuing teacher training programs through new technologies.

Keywords: Continuing teacher training, New technologies, Virtual environments, Distance education programs

\footnotetext{
${ }^{1}$ Licenciada em Pedagogia (Unipar), Especialista em Gestão Educacional (Unipan), Especialista em Língua Inglesa (FAG), Mestranda em Ensino de Ciências Humanas (Ppgen) - Universidade Tecnológica Federal do Paraná, Campus de Londrina - Utfpr-LD.

${ }^{2}$ Doutor em Ciência Política (Unicamp), Docente e Pesquisador da Universidade Tecnológica Federal do Paraná, Campus Cornélio Procópio/PR, Curso de Licenciatura em Matemática do Departamento de Matemática da Utfpr-CP e membro permanente do Programa de Pós-Graduação em Ensino (Ppgen) da Universidade Tecnológica Federal do Paraná, Campus de Londrina/PR - Utfpr-LD.

3 Doutora em Linguística e Língua Portuguesa (Unesp), Docente e Pesquisadora da Universidade Tecnológica Federal do Paraná, Campus Londrina/PR. Coordenadora e Docente do Programa de Mestrado Profissional em Ciências Humanas, Sociais e da Natureza (Ppgen) da Universidade Tecnológica Federal do Paraná, Campus de Londrina/PR - Utfpr-LD.
}

Revista Educação Online, n. 19, jun-ago 2015, p. 1-19 


\section{Introdução}

O tema "formação continuada" não é algo novo. Muito se tem discutido e analisado com relação às propostas existentes e as possíveis contribuições que elas têm trazido aos professores de maneira geral. Vários autores apresentam discussões sobre essa temática e ressaltam sua relevância, como Nóvoa (1992), Candau (1996), Nascimento (2000), Szewczyk (2005) e Pimenta (2002). Já Dal Molin (2003) e Hack (2011) abordam o mesmo assunto, destacando o papel dos ambientes virtuais nesse processo.

Tendo em vista a dinâmica da sociedade atual, é preciso repensar os caminhos e os meios de estudo que estão sendo oferecidos aos professores hoje. As dificuldades e os desafios enfrentados em sala de aula são muitos. O professor, que está à frente desse processo e comprometido com o aprendizado dos seus alunos, precisa estar em constante busca por conhecimento, ou seja, um profissional que valorize a investigação como estratégia de ensino, que desenvolva a reflexão crítica da sua prática e que esteja sempre preocupado com a sua formação.

A formação continuada passa a ser um dos pré-requisitos básicos para a atualização do professor, pois é através do estudo, da pesquisa, da reflexão e do constante contato com o conhecimento, que é possível avançar profissional e pessoalmente.

Conforme o previsto em lei, o Estado tem o dever de ofertar a formação continuada aos profissionais do magistério: "A União, o Distrito Federal, os Estados e os Municípios, em regime de colaboração, deverão promover a formação inicial, a continuada e a capacitação dos profissionais de magistério." ( $\$ 1^{\circ}$ do art. 62 - Lei

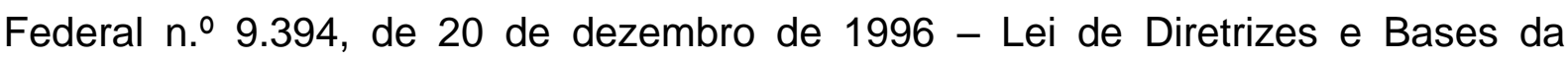
Educação Nacional - Ldben).

Fica mais difícil o professor mudar seu modo de pensar o fazer pedagógico, se não tiver a oportunidade de vivenciar novas experiências, novas pesquisas, novas formas de ver e pensar suas aulas e a escola. Vale ressaltar que a formação continuada não descarta a necessidade de uma boa formação inicial, mas, para aqueles profissionais que já estão atuando, ela se faz relevante, uma vez que o avanço dos conhecimentos, as tecnologias e as novas exigências do meio social e político impõem ao profissional, à escola e às instituições formadoras, a continuidade e o aperfeiçoamento da formação profissional. 
Além de estar assegurado em lei o direito de o professor de participar de propostas de formação continuada, ainda na Ldben, fica definido o local de trabalho como o lugar que essas capacitações deverão ocorrer:

Garantir-se-á formação continuada para os profissionais a que se refere o caput, no local de trabalho ou em instituições de educação básica e superior, incluindo cursos de educação profissional, cursos superiores de graduação plena ou tecnológicos e de pós-graduação. (Parágrafo Único do art. 62 - Lei n.ำ 9.394, de 20 de dezembro de 1996).

Candau (1996) corrobora com o previsto na Ldben, ao considerar a escola como o "lócus da formação de professores". No entanto, para que realmente a formação continuada atinja seu objetivo, ela precisa ser significativa para o professor. Segundo Nascimento (2000), as propostas de capacitação dos docentes têm apresentado baixa eficácia. Algumas das razões apontadas são: a desvinculação entre teoria e prática; a ênfase excessiva em aspectos normativos; e a falta de projetos coletivos e/ou institucionais.

De acordo com Candau (1996), é de extrema importância que um programa de formação continuada seja capaz de qualificar professores, por meio de programas que partam das necessidades do dia a dia do profissional da educação e proponham temas e métodos de operacionalização que busquem auxiliar o docente a refletir e a enfrentar as adversidades vivenciadas na prática. Em síntese, a relação entre os saberes teóricos e os saberes práticos necessários para uma boa qualificação é fundamental.

É oportuno reforçar a ideia da articulação entre teoria e prática, já que, como salienta Pimenta (2002), não se pode cometer o engano de pensar que apenas a reflexão na prática e sobre a prática será suficiente para o encaminhamento adequado de todos os problemas enfrentados no fazer pedagógico.

Embora a formação continuada deva atender às necessidades do professor no seu cotidiano, não pode ser entendida como um receituário, ou seja, um conjunto de modelos metodológicos e de conteúdos que, se seguidos, serão a solução para os problemas. Os processos de formação continuada podem ser valiosíssimos, se conseguirem aproximar os pressupostos teóricos e a prática pedagógica. Ainda de acordo com o mesmo autor, a formação continuada deve ser capaz de conscientizar o professor de que teoria e prática são "dois lados da mesma moeda" (CHIMENTÃO, 2009, p. 5), que a teoria o ajuda a compreender melhor a sua prática e a lhe dar 
sentido e, consequentemente, que a prática proporciona melhor entendimento da teoria ou, ainda, revela a necessidade de nela fundamentar-se.

\section{Fundamentação teórica}

Os cursos e propostas de formação continuada em ambientes virtuais têm crescido de forma considerável ultimamente. Ludovico e Dal Molin (2013) afirmam que as rápidas mudanças ocasionadas pelas transformações tecnológicas evidenciaram que a educação a distância vem crescendo, e que essa é uma modalidade de estudos democrática.

Devido à grande expansão dos recursos tecnológicos e do fácil acesso à Internet, essa tem sido uma alternativa de trabalho muito frequente quando 0 assunto é estudar. Nos segmentos privados, principalmente, essa prática tem deixado de ser exceção em muitos casos, e tem-se optado pela oferta de cursos a distância por diversos motivos, dentre eles, talvez o mais relevante, a flexibilidade de tempo e local que essa modalidade de estudos apresenta. Conforme afirma Hack (2011), "seria uma maneira de facilitar e flexibilizar o acesso ao saber, favorecendo a contextualização e a diversificação das interações" (HACK, 2011, p. 14).

Sem dúvida, as tecnologias vêm modificando todas as áreas da sociedade, e o impacto é sentido em todas as esferas da vida social, seja no trabalho, no lazer e nas relações pessoais, principalmente na maneira como nos comunicamos. De acordo com Dal Molin (2003):

Não há como negar que este novo contexto mediático tem grande importância na expansão do saber, na facilitação da produção de novos conhecimentos, nos avanços em todas as áreas e setores da vida, pois o saber partilhado e mutuamente construído, veiculado nas redes é a matéria-prima de gestação de um novo espaço antropológico. (p. 75)

Esse fenômeno não passa despercebido no ambiente escolar. Cada vez mais, as tecnologias digitais se inserem no interior da escola, tanto por iniciativa dos alunos quanto dos professores, e existem muitas pesquisas desenvolvidas e ainda em desenvolvimento que estudam essa inserção tecnológica na escola.

Porém, o fato é que a tecnologia digital se tornou parte integrante do mundo moderno, e a educação, como parte desse contexto, não pode ficar alheia a ela. É papel das instituições e dos professores integrá-la no âmbito escolar, utilizando esses recursos como novas metodologias de ensino, assim como tirando proveito 
dessas ferramentas, como novas possibilidades de estudos e aperfeiçoamento profissional.

Conforme os estudos de Dal Molin (2003), uma formação continuada por via do ambiente virtual pode oferecer alternativas diferenciadas, como a possibilidade de alcançar um maior número de pessoas e a oportunidade de as pessoas estudarem, refletirem, produzirem e realizarem suas tarefas, no lugar e no momento que Ihes for mais oportuno, facilitando a organização e a conciliação com demais atividades diárias.

No entanto, para que isso aconteça, o professor precisa estar preparado para lidar com os diferentes aparatos tecnológicos que estão ao seu alcance. Segundo Dal Molin (2003), faz-se necessária a capacitação das pessoas para trabalhar com a tecnologia, pois, no mundo em transformação em que se vive hoje, a tecnologia é um instrumento essencial de trabalho:

Num mundo em transformação, no qual a tecnologia, dia a dia, é o link da mente e um instrumento essencial de trabalho, as instituições de ensino não podem preparar os futuros profissionais para um mundo de subalternidade, tanto do ponto de vista individual quanto na perspectiva do coletivo. Enfatizamos, portanto, que a inclusão digital significa muito mais do que ensinar o emprego da tecnologia ou disponibilizar o acesso à rede: faz-se necessário um trabalho sério e aprofundado a fim de conhecer as demandas relativas à capacitação dos cidadãos para a lida com a tecnologia. (DAL MOLIN, 2003, p.56)

As instituições de ensino não podem preparar os futuros profissionais desconsiderando esse aspecto, tanto do ponto de vista individual quanto na perspectiva do coletivo. A autora enfatiza, portanto, que a inclusão digital vai muito além de apenas ensinar o emprego da tecnologia.

Cientes da influência das tecnologias no ensino, a formação continuada através de ambientes virtuais pode despertar nos professores um espírito investigativo e autônomo, fazendo com que ele se sinta o principal ator no processo de busca por conhecimento, uma vez que o estudante é quem toma a iniciativa nas atividades nessas propostas de formação e é o principal responsável pelo cumprimento de prazos e objetivos.

De acordo com Szewczyk (2005), é necessário que o professor reconheça a importância de sua própria formação, buscando aprimoramento continuado, para atender às exigências do mundo atual, através de iniciativas pessoais ou acompanhando as formações propiciadas pelo sistema educacional. Quando o 
professor percebe o quanto seu trabalho pode ser determinante na formação de seus alunos, ele o desenvolve com mais entusiasmo e criatividade.

É importante destacar a realidade escolar de hoje, bem como o perfil dos professores que atuam junto às instituições públicas de ensino. Há de se considerar a carga horária de trabalho desses profissionais, as possibilidades reais de acesso e manejo com as tecnologias digitais, tanto para uso com os alunos em sala, tanto para uso próprio em pesquisas e planejamentos de aula, para se pensar quais formatos ou modelos de formação continuada melhor contemplariam as necessidades e a realidade desses professores.

Em outras palavras, as propostas de formação continuada por via de ambientes virtuais visam a acrescentar e contribuir com a capacitação dos professores, oferecendo uma oportunidade a mais de estudos e interação com outros profissionais. Todavia, é necessário considerar que os docentes necessitam de um espaço para formação, concentrado na sua atividade cotidiana, que contemple os problemas e as necessidades específicas da sua comunidade escolar. De acordo com Candau (1996),

A formação continuada não pode ser concebida como um processo de acumulação (de cursos, palestras, seminários etc., de conhecimentos ou técnicas), mas, sim, como um trabalho de reflexibilidade crítica sobre a prática de (re)construção permanente de uma identidade pessoal e profissional, em interação mútua. (p.150)

Nesse sentido, é relevante questionar se, do ponto de vista dos professores, essas iniciativas - de formação continuada a distância - são viáveis, e se, de fato, são aceitas e recebidas pelos docentes como uma possibilidade significativa de aperfeiçoamento profissional.

\section{Metodologia de pesquisa}

Com o objetivo de levantar dados com relação ao entendimento dos professores sobre o tema desse artigo, a metodologia de pesquisa aplicada pautouse em uma abordagem qualitativa, uma vez que se buscou não apenas quantificar e descrever dados, mas também analisar as opiniões e as informações que os professores possuíam sobre a formação continuada e discuti-los com a teoria existente. Segundo Minayo (1998), as pesquisas qualitativas mostram que, na produção de conhecimentos sobre os fenômenos humanos e sociais, é muito mais 
interessante compreender e interpretar seus conteúdos do que puramente descrevêlos.

Para tanto, realizou-se uma pesquisa de campo em uma escola municipal, de porte médio, de uma cidade do oeste do Paraná. No que diz respeito à pesquisa de campo, Severino (2007) explica que, nesse tipo de pesquisa, o objeto de estudo é abordado em seu ambiente próprio, e a coleta dos dados é realizada nas condições naturais em que as situações acontecem. Assim, são diretamente observados.

Escolheu-se a técnica de aplicação de questionários, em virtude de se tratar de um ambiente de trabalho no qual o pesquisador já havia trabalhado. Dessa forma, o uso dessa técnica contribuiu para buscar a objetividade nas respostas dos vinte e três professores e professoras envolvidos na pesquisa. Aliás, é válido ressaltar o número significativo obtido no retorno dos questionários: dos vinte e seis questionários aplicados, vinte e três foram respondidos, ou seja, aproximadamente noventa por cento do total proposto inicialmente.

O questionário, composto por cinco questões (quatro fechadas e uma aberta), proporcionou a coleta de informações de forma sistemática e no próprio ambiente escolar. De acordo com Severino (2007),

O questionário é um conjunto de questões, sistematicamente articuladas, que se destinam a levantar informações escritas por parte dos sujeitos pesquisados, com vistas a conhecer a opinião dos mesmos sobre os assuntos em estudo (...). Podem ser questões fechadas ou questões abertas. No primeiro caso, as respostas serão escolhidas dentre as opções pré-definidas pelo pesquisador; no segundo, o sujeito pode elaborar as respostas com suas próprias palavras, a partir de sua elaboração pessoal. (p. 125-126)

As perguntas do questionário aplicado foram apresentadas e analisadas individualmente, seguindo a ordem em que apareceram no documento impresso e considerando a abordagem teórica referida no texto. A partir disso, identificaram-se possíveis reflexões e considerações relevantes sobre o assunto proposto.

\section{Análise e discussão dos dados}

A análise dos dados obtidos foi organizada em cinco seções, sendo uma para cada pergunta do questionário utilizado na pesquisa. Essa organização foi assim pensada, para facilitar a visualização e a compreensão das informações colhidas na realização deste estudo. 


\section{Experiência profissional}

A primeira questão abordada no formulário dizia respeito ao tempo de magistério dos professores. Dos entrevistados, constatou-se que doze possuem entre cinco e dez anos de atuação, nove possuem quinze anos ou mais de magistério e apenas dois se encontram no início da carreira docente, situando-se entre dois e cinco anos de profissão.

Com base nesses dados, é possível considerar que o perfil dos professores questionados apresenta certa experiência profissional, a julgar pelos anos trabalhados, ou seja, o tempo de atuação no magistério. Porém, é relevante analisar o quanto e de que forma o tempo de serviço realmente interfere e influencia na formação do profissional, pois, se a prática de determinado professor se manteve a mesma durante vários anos, ou seja, se sua postura e metodologia de ensino nada evoluíram durante um espaço de tempo, pode ser que não haja diferenças significativas entre um professor com cinco ou dez anos de carreira.

É o que afirma Nóvoa (2007), ao citar uma contribuição de John Dewey sobre a prática reflexiva, de que há um déficit de práticas na formação e de reflexão dessas práticas. Nas palavras de John Dewey (1959), que nos anos 1930, inventa o conceito de professor reflexivo, "o que é essencial é a reflexão sobre as práticas" (DEWEY, 1959, p. 120). Em uma de suas palestras, um professor vira-se para Dewey e diz: "o senhor abordou várias teorias, mas eu sou professor há dez anos, eu sei muito mais sobre isso, tenho muito mais experiência nessas matérias"; então, Dewey volta-se para o professor e questiona: "tem mesmo dez anos de experiência profissional ou apenas um ano de experiência repetida dez vezes?" (NÓVOA, 2007, p. 16).

Candau (1996) destaca a importância de se reconhecer e valorizar o saber docente no contexto das práticas de formação contínua, especialmente, dos saberes das experiências vivenciadas, tendo em vista que o saber docente é construído levando em conta tais saberes e experiências.

Contudo, o objetivo de se questionar o tempo de magistério no presente artigo está relacionado a saber se o professor em questão teve tempo suficiente para vivenciar alguns aspectos que envolvem a sua carreira profissional, a ponto de fazer uma breve análise a respeito de uma parte importante dela, que é a formação continuada. Dessa maneira, entende-se que a grande maioria dos professores interrogados tem um tempo de atuação satisfatória para responder e refletir sobre as propostas de formação continuada já vivenciadas em sua carreira docente. 


\section{A tecnologia no dia a dia do professor}

A segunda questão se referia ao uso do computador pelos professores para fins profissionais, ou seja, se os professores utilizam essa ferramenta no seu dia a dia para auxiliar o seu trabalho. Dos vinte e três participantes da pesquisa, apenas um afirmou não fazer uso do computador para esse fim. Logo, entende-se que o uso dessa tecnologia é marcado tanto por professores em início de carreira, quanto por aqueles que já possuem um tempo significativo de experiência.

As tecnologias digitais vêm conquistando seu espaço na vida das pessoas de forma intensa, seja em momentos de lazer ou de trabalho. $O$ acesso instantâneo a um número ilimitado de informações leva as pessoas a optarem por essa ferramenta de pesquisa, ao invés de recorrerem a outras fontes. Porém, é preciso refletir acerca do uso do computador. De que forma os professores o utilizam para fins profissionais? Para o preparo de aulas, pesquisa, leitura, estudo, produção de material? Por mais que essa pergunta no questionário não exija do professor uma resposta mais específica com relação a esse uso, cabe uma reflexão a respeito das reais condições que os professores têm de utilizar esse recurso de forma significativa para sua vida profissional.

Por meio de uma breve pesquisa pelo site de uma universidade estadual do Paraná, identificou-se que cinco cursos de licenciatura, sendo: ciências biológicas, matemática, letras (português-inglês, português-espanhol e português-italiano), pedagogia e licenciatura em educação do campo não apresentam, em suas matrizes curriculares, nenhuma discussão sobre as tecnologias digitais, seja como parte do processo educativo dos alunos ou na formação dos futuros professores. Nenhum dos cursos traz, em suas grades curriculares, disciplinas que tratem da temática tecnologia, demonstrando o descompasso entre o processo de formação inicial dos professores e as exigências que esses enfrentam nas escolas devido às mudanças da sociedade contemporânea.

A ausência de disciplinas que discutam tecnologia, observada nos cursos de licenciaturas, é possivelmente a realidade da maior parte das universidades do país, o que é preocupante, pois elas não estão contribuindo para a formação de professores que necessitarão trabalhar com as tecnologias em contexto escolar. Nóvoa (1995) reforça a ideia de que os cursos de formação de professores necessitam propor uma formação do profissional professor que ocorra dentro das 
necessidades e exigências sociais atuais, a partir da cooperação entre aqueles que discutem a educação e a universidade e aqueles que fazem parte da ação educativa, os futuros profissionais da educação. Dal Molin (2003) corrobora as afirmações de Nóvoa, ao sustentar que,

A formação de educadores requer, por parte das universidades, uma revisão de suas grades curriculares que se mostram inoperantes e inadequadas à formação de educadores com o perfil necessário às novas práticas educativas. Portanto, a universidade deve evoluir na direção de uma tessitura curricular hipertextual capaz de entretecer e interconectar pontos que permitam a flexibilidade e a polifonia de sentidos. (p. 165)

O licenciando em formação deve ser exposto às situações que enfrentará no campo profissional, bem como devidamente preparado, a fim de iniciar sua prática, consciente com todas as demandas e problemas da educação hoje. Isso nos leva a questionar se a formação dos novos professores é realmente satisfatória e eficaz. Nóvoa (1995) afirma que "não há ensino de qualidade, nem reforma educativa, nem inovação pedagógica, sem uma adequada formação de professores” (p.9).

Contudo, é importante destacar que, embora muito possivelmente os professores participantes da pesquisa não tenham recebido formação a respeito de tecnologias em seus cursos de licenciatura, quase cem por cento deles afirma valerse do uso do computador para realizar seu trabalho como professor. Destaca-se aqui uma grande iniciativa pessoal de cada professor, na busca por atender às

necessidades tecnológicas atuais e pela sua inserção nesse contexto. É certo, no entanto, que, apesar da maneira como utilizam o computador (pesquisa, estudo, preparo de aulas, produção de material etc.), esses profissionais estão em constante contato com essa tecnologia digital.

\section{Experiências posteriores}

A terceira questão apresentada aos professores relativa a experiências posteriores em programas de formação continuada a distância, ou seja, se eles já haviam participado dessa modalidade de formação continuada, em algum momento de sua carreira. Como resposta, dentre os vinte e três professores, doze afirmaram já ter participado de cursos de formação continuada a distância, e onze afirmaram não terem tido experiência até o momento. Assim, pode-se dizer que o grupo de 
professores questionados divide-se em duas partes, praticamente iguais, com relação a essa questão.

Os programas de formação continuada a distância estão cada vez mais presentes nas propostas de instituições privadas e até mesmo de secretarias da educação dos municípios, devido a algumas facilidades que eles apresentam, como flexibilidade de local e horário e custos menos elevados. Como dizem Ludovico \& Dal Molin (2013), os cursos a distância podem alcançar um grande número de interessados devido à flexibilidade em relação ao tempo e ao lugar. Além disso, partilham de uma dinâmica peculiar: a possibilidade da integração de mídias interativas, oportunizando que os cursistas estudem, reflitam e produzam suas tarefas no melhor momento para cada um.

Tais características, presentes nas propostas de formação continuada a distância, levam muitos professores a optarem por esses programas, considerando que, muitas vezes, as atribuições do dia a dia do professor o impedem de frequentar cursos presenciais, ora por problemas de deslocamento até as instituições, ora por não estar disponível nos dias e nos horários em que determinado curso é ofertado.

No entanto, Hack (2011) afirma existir um perfil de sujeito com algumas características básicas e necessárias à modalidade de estudos a distância, como por exemplo, ter certos critérios, não só acadêmicos (rigor e clareza científicas), mas também empresariais (por exemplo, tem de saber cumprir prazos e estimar custos), de forma autônoma.

Há também aqueles professores que não tiveram contato ainda com essa modalidade de formação, e os motivos podem ser muito variados, como: não ter afinidade em estudar através do computador e da Internet, ou até mesmo não possuir um computador em casa e/ou um acesso à Internet, ou ainda, preferir a presença física de um professor e dos colegas. Deve-se considerar também aqueles que não tiveram oportunidade de se inscrever em um curso a distância e, dessa forma, não têm condições de avaliar essa modalidade de estudos.

\section{Eficiência da formação continuada}

A quarta pergunta do questionário estava relacionada à confiança dos professores com relação às propostas de formação continuada em geral, ou seja, se eles acreditam na eficácia das capacitações em serviço que lhes são ofertadas. 
Como resultado, dos vinte e três professores, dois demonstraram desacreditar da eficácia da proposta, e vinte e um afirmaram acreditar na eficiência da formação continuada.

Assim, é possível afirmar que, mesmo professores experientes, com mais de dez anos de magistério, ainda têm expectativas no que diz respeito ao seu processo de formação contínua. Essa informação é relevante, pois demonstra que os docentes têm interesse em se manter estudando ao longo dos anos. Por mais que essa motivação venha de fontes diversas, o resultado é positivo: os professores sustentam a ideia de que é necessário continuar estudando e aperfeiçoando seus saberes quando se está em exercício da função docente, e que isso é possível através dos programas de formação continuada, sejam eles a distância ou presenciais.

De acordo com Nóvoa (1992), frequentar cursos de formação continuada é investir na carreira e, gradativamente, construir a identidade docente. Segundo esse autor, a formação deve estar pautada em uma perspectiva crítico-reflexiva, que venha a contribuir com os professores na construção de sua autonomia docente. Estar em formação significa um constante investimento pessoal, baseado em iniciativas e projetos próprios, com vistas à construção de uma identidade profissional.

Contudo, por mais que a maioria dos professores participantes da pesquisa conte com a formação continuada, essa ainda apresenta muitas fragilidades e desafios. Segundo o mesmo autor, a capacitação dos professores é, por vezes, demasiadamente teórica ou demasiadamente metodológica, e há carência de práticas, de reflexão sobre as práticas.

\section{Pontos positivos e negativos: diferentes olhares}

A quinta e última pergunta, questão aberta, possibilitou aos professores elaborarem suas respostas sobre os pontos positivos e negativos que eles consideravam estarem presentes na modalidade de formação continuada a distância.

Como fatores positivos, de acordo com 0 gráfico 1 , as respostas dos professores foram organizadas em sete categorias, de acordo com semelhança e/ou proximidade de elementos: flexibilidade de estudo (horário e local) - dez 
professores; possibilidade de troca de ideias e informações - quatro professores; acréscimo de conhecimentos de modo geral - três professores; materiais mais completos do que nas formações presenciais - um professor; estudos mais aprofundados do que nas formações presenciais - um professor; afirmaram não terem condições de responder a essa questão, por nunca terem feito esse tipo de formação - dois professores; não responderam a essa questão por razões desconhecidas - dois professores.

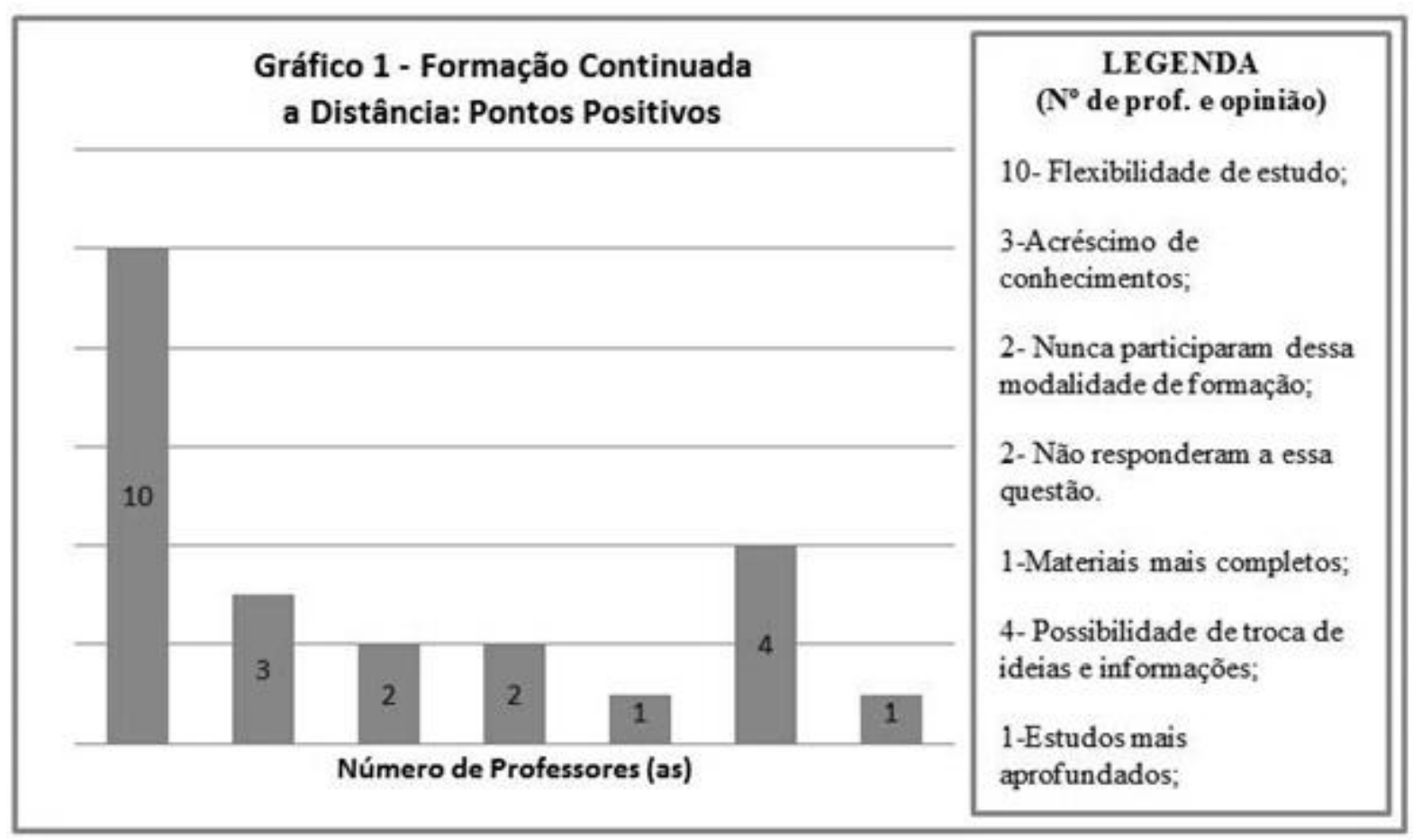

Fonte: referência excluída para assegurar anonimato.

Como fatores negativos, de acordo com o gráfico 2, as respostas dos professores também foram classificadas em sete categorias, com as respostas organizadas por semelhança e/ou proximidade de elementos: falta de interação com os colegas - seis professores; propostas distantes da realidade da escola - três professores; receio de essa modalidade de formação continuada não ser reconhecida para progressão na carreira - três professores; falta da presença física do professor - um professor; não citaram pontos negativos - seis professores; afirmaram não terem condições de responder a essa questão, por nunca terem feito esse tipo de formação - dois professores; não responderam a essa questão por razões desconhecidas - dois professores. 


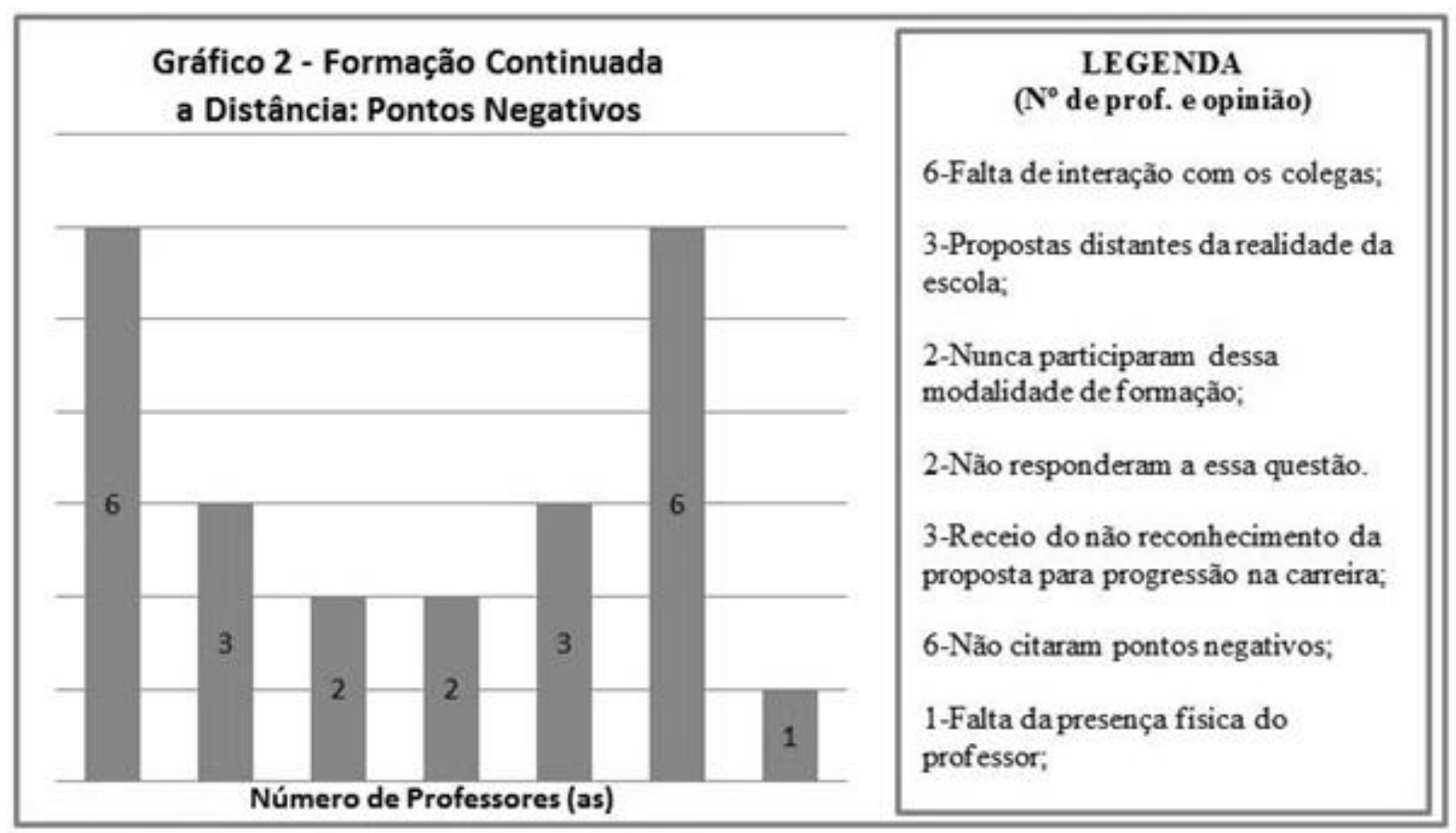

Fonte: referência excluída para assegurar anonimato.

A flexibilidade de estudo que a formação continuada a distância oferece destaca-se como um ponto positivo muito forte, pois dez professores assim 0 afirmaram, reforçando a ideia de que a rotina de trabalho dos docentes nos dias de hoje é muito intensa e os impossibilita várias vezes de frequentarem cursos presenciais. Associada a essa questão, pode-se considerar a possibilidade de troca de ideias e informações como um argumento significativo quando se trata de formação a distância, citada por quatro professores. Isso porque, uma vez que essa modalidade pode proporcionar o contato e a interação com profissionais de lugares distintos, extrapola as fronteiras do município, do estado ou até mesmo do país em que o docente se encontra, ampliando e enriquecendo o seu campo de visão sobre aspectos que dizem respeito ao seu trabalho e a sua profissão.

Para que os objetivos da formação a distância realmente ocorram, é necessário que os professores que optarem por esse modelo de estudos estejam cientes de algumas atribuições básicas que estarão sob sua responsabilidade. Segundo Hack (2011), na modalidade a distância, o compromisso do aluno por sua aprendizagem é maior, pois ele próprio deverá organizar seu tempo de estudos, não depender da imposição de uma lista de chamada para realizar as atividades, assim como precisará desenvolver autodisciplina e estratégias de motivação para a permanência no processo. 
Além disso, de acordo com os estudos do mesmo autor, as pessoas que estiverem dispostas a estudar com autonomia, por meio de cursos a distância, deverão adaptar a sua postura ao processo desse modelo de ensino-aprendizagem: participar ativamente das atividades desenvolvidas em ambientes virtuais (fóruns, salas de bate-papo etc.); administrar o tempo e as atividades cotidianas com vistas a dar conta das interações e conseguir um relacionamento mais intenso com os colegas, tutores e professores; aprender a selecionar as inúmeras informações as quais será submetido diariamente; entre outras questões.

Ainda com referência aos aspectos favoráveis à educação a distância, quanto às considerações dos professores sobre o acréscimo de conhecimentos, materiais mais completos e estudos mais aprofundados do que nas formações presenciais, apesar de não ser um número significativo de docentes compartilhando essa opinião, pode-se entender que a autonomia de quem estuda a distância leva 0 estudante à pesquisa, à leitura e à busca de conhecimentos e respostas, resultando em estudos aprofundados. Nesse sentido, as propostas de educação a distância corroboram a afirmação de Nóvoa (1992), "os professores têm que se assumir como produtores da sua profissão" (p. 17), ou seja, é o docente, no exercício de sua autonomia, que precisa investir tempo e energia na busca por desempenhar um trabalho de qualidade e condizente com as exigências da sociedade atual.

No que diz respeito aos pontos negativos levantados pelos professores, temse duas questões mais relevantes e outras três secundárias. Essa relevância se caracteriza pelo número de professores com a mesma opinião. Seis docentes consideraram como negativa a falta de interação com os colegas na proposta de formação continuada a distância. Considerando que, na educação a distância, existe interação entre colegas e professores em caráter virtual, acredita-se que esses professores sentem a necessidade da presença física de outras pessoas quando estão estudando. É importante ressaltar que essa "falta de interação" mencionada pelos pesquisados, foi atribuída exclusivamente à interação com os colegas, ou seja, não fizeram referência à figura do professor nesse ponto. Em contraposição, Nóvoa (2007) atenta para o seu papel no processo de formação continuada, reforçando a opinião de um dos docentes pesquisados com relação à necessidade da presença física do professor:

Podem inventar tecnologias, serviços, programas, máquinas diversas, umas a distância outras menos, mas nada substitui um bom professor. Nada substitui o bom 
senso, a capacidade de incentivo e de motivação que só os bons professores conseguem despertar. Nada substitui o encontro humano, a importância do diálogo, a vontade de aprender que só os bons professores conseguem promover. (p.18)

Teorias de aprendizagem pautadas na interação social, como a de Vygotsky, afirmam que o desenvolvimento da inteligência é produto da convivência humana, ou seja, o homem só se constrói homem na presença do outro. As relações sociais que se estabelecem na convivência em sociedade são extremamente ricas, o diálogo, a cooperação, a empatia, o contato humano, entre outros aspectos, são muito valorizados pelos professores. Nóvoa (1992) observa que o diálogo e a interação entre os docentes são fundamentais para consolidar os saberes emergentes da prática profissional, defendendo a criação de redes coletivas de trabalho como um fator decisivo de socialização profissional e de afirmação de valores próprios da profissão docente.

Em contrapartida, o mesmo número de professores (seis) não citou pontos negativos nos programas de formação continuada a distância. As razões podem ser as mais variadas possíveis, mas o fato de as duas situações estarem apresentadas na mesma pergunta no questionário (pontos positivos e negativos) minimiza a possibilidade de o professor não ter marcado os pontos negativos acidentalmente, pois, ao descrever as características positivas, é possível se pensar nas negativas, quase automaticamente. Contudo, não citá-las não significa que eles não existam, isto é, não se pode afirmar que esses professores(as) acreditam que não haja fatores negativos associados a esse modelo de formação. Logo, esse dado pode se caracterizar como indefinido e questionável.

As outras duas questões apontadas pelos professores como negativas referem-se ao fato de as propostas de formação a distância estarem muito alheias à realidade da escola em que atuam, e outro grupo destaca o receio de essa modalidade não ser reconhecida para progressão na carreira. Sobre essa última preocupação levantada pelos professores, o parágrafo segundo, do artigo 62, da Lei de Diretrizes e Bases da Educação Nacional ( $n^{\circ}$. 9.394/96), assegura que "a formação continuada e a capacitação dos profissionais do magistério poderão utilizar recursos e tecnologias de educação a distância", isto é, está previsto em lei que os cursos de capacitação docente poderão fazer uso de tecnologias e serem oferecidos em ambientes virtuais, a distância. Fica evidente que esse grupo defende como 
fundamental a possibilidade de elevação de nível na carreira proporcionada pela participação em cursos de formação continuada.

A afirmação de que as propostas de formação a distância são alheias à realidade da escola é um ponto muito inquietante, pois parece que essa característica pode aplicar-se às propostas de formação presencial também, uma vez que diz respeito ao conteúdo da capacitação em si, e não à metodologia ou ao seu formato. O real problema por trás da afirmação desses professores está no conteúdo das capacitações continuadas de modo geral, ou seja, o que se entende por formação continuada, o que se espera de uma formação continuada e o que de fato acontece nesses encontros de formação. Conforme ressalta Nóvoa (1992), "a formação deve estar centrada na escola" (p.17), e não preocupada em atender os objetivos do sistema, deixando de lado o desenvolvimento profissional dos professores e o desenvolvimento organizacional das escolas. Isso é inaceitável, segundo o autor, mas é uma constante. É preciso reconhecer as deficiências dos programas atuais de formação de professores e situar a nossa reflexão para além das discussões tradicionais (conteúdos científicos versus questões pedagógicas, disciplinas teóricas versus disciplinas metodológicas etc.), sugerindo novas maneiras de pensar a problemática da formação de professores.

Enfim, após a apresentação e análise dos aspectos positivos e negativos descritos pelos professores, é possível observar que, segundo os docentes que participaram da pesquisa, destacam-se duas características nos programas de formação continuada a distância: uma positiva e outra negativa. A positiva, com relação à versatilidade presente nessas propostas, o que permite às pessoas estudarem em suas casas, nos horários que lhes forem mais apropriados. A negativa diz respeito à incapacidade de interação com outros colegas cursistas, isto é, interação essencialmente por meio de contato físico, algo que a educação a distância não é capaz de proporcionar.

\section{Considerações finais}

A formação continuada sempre será alvo de discussões e pesquisas educacionais. Após análise do trabalho aqui proposto, acredita-se ter apresentado algumas reflexões acerca da educação a distância aplicada à formação continuada de professores, no sentido de indicar alguns caminhos de como os docentes estão 
recebendo essas propostas nas escolas. Porém, tem-se a clareza de que há muito que se estudar ainda sobre esse assunto, como por exemplo, as características e/ou ferramentas dos ambientes virtuais que mais correspondem às expectativas dos professores, ou até mesmo procurar identificar quais regiões brasileiras aderem mais à educação a distância no momento e o que significa a opção por essa alternativa de estudos em cada região do país.

A formação continuada, seja presencial ou em ambientes virtuais, deve estimular a autonomia e o pensamento crítico-reflexivo. Cientes da influência e da necessidade das tecnologias no ensino, a formação continuada para professores não pode se eximir disso. Pelo contrário, ela deve fazer uso desses recursos para, cada vez mais, deixar os profissionais da educação familiarizados com ela, percebendo a sua aplicabilidade na escola e na sua própria capacitação enquanto professor.

De acordo com os dados obtidos na pesquisa, muitos profissionais atribuem à educação a distância a possibilidade de se estudar em casa, sendo essa uma característica citada como positiva pelos docentes que participaram desse estudo. Em contrapartida, um aspecto marcado nas respostas dos professores como negativo na educação a distância foi à impossibilidade de interação com outros colegas cursistas, aspecto que permite perceber a expectativa que os docentes têm de trocar experiências e dialogar com outros colegas de profissão, nesses momentos de formação contínua.

As rápidas mudanças ocasionadas pelas transformações tecnológicas colocaram em evidência a educação a distância. Pode-se considerar que essa modalidade é democrática, devido ao apoio das tecnologias digitais que levam à superação de alguns problemas, tais como a distância, o tempo, entre outros. Porém, os benefícios dessa modalidade de educação só podem ser vividos de fato por aqueles que possuem domínio da ferramenta tecnológica e se sentem inseridos nesse meio. Além disso, conforme os docentes participantes desta pesquisa afirmaram, a educação a distância pode não contemplar todas as necessidades educacionais das pessoas, posto que não viabiliza a interação e o contato entre os cursistas de uma forma mais próxima. Entretanto, uma vez que atenda às demandas da escola com qualidade, as propostas de formação continuada em ambientes virtuais podem ser uma possibilidade inovadora a favor da educação. 


\section{Referências bibliográficas}

BRASIL. Ministério de Educação e Cultura. LDB - Lei no 9394/96, de 20 de dezembro de 1996. Estabelece as diretrizes e bases da Educação Nacional. Brasília: MEC, 1996.

CANDAU, V. M. F. A formação continuada de professores: tendências atuais. In: REALI, Aline de M. R.; MIZUKAMI, M. da G. N. (Orgs.). Formação de professores: tendências atuais. São Carlos: EDUFSCar, 1996.

CHIMENTÃO, Lilian Kemmer. O significado da formação continuada docente. In: CONGRESSO NORTE PARANAENSE DE EDUCAÇÃO FÍSICA ESCOLAR. 2009. Londrina. Anais: 4 CONPEF. Universidade Estadual de Londrina, 2009.

DAL MOLIN, Beatriz Helena. Do tear à tela: uma tessitura de linguagens e sentidos para processo de aprendência. Florianópolis, 2003. Tese (Doutorado em Engenharia de Produção de Mídia e Conhecimento) - CTE - UFSC. Florianópolis, 2003.

DEWEY, John. Como pensamos. 3 ed. São Paulo: Editora Nacional, 1959.

HACK, Josias Ricardo. Introdução à educação a distância. Florianópolis: LLV/CCE/UFSC, 2011.

LUDOVICO, F. M.. DAL MOLIN, B. H.. Educação a distância: uma avaliação. In: Congresso de educação da FAG: Formando Educadores para a Diversidade, 1, 2013, Cascavel. Anais... Cascavel, 2013.

MINAYO, M. C. Pesquisa social: teoria, método e criatividade. Petrópolis: Vozes, 1998.

NASCIMENTO, M. das G. A formação continuada dos professores: modelos, dimensões e problemática. Caderno Temático, n. 5, p.84-85, jun 2000. Ciclo de Conferências da Constituinte Escolar.

NÓVOA, António (Coord.). Os professores e a sua formação. Lisboa: Dom Quixote, 1992.

. O passado e o presente dos professores. In: . Profissão professor. Portugal: Porto, 1995. p.13-34.

. Desafios do trabalho do professor no mundo contemporâneo.

(Livreto). São Paulo: Via Impressa Design Gráfico, 2007. Disponível em: <http://www.sinprosp.org.br/arquivos/novoa/livreto_novoa.pdf>. Acesso em: 23/09/2014.

PIMENTA, Selma Garrido. Professor reflexivo: construindo uma crítica. In: PIMENTA, Selma Garrido; GHEDIN, Evandro (Orgs.). Professor reflexivo no Brasil: gênese e crítica de um conceito. São Paulo: Cortez, 2002. p.34.

SEVERINO, Antônio Joaquim. Metodologia do trabalho científico. 23ed. rev. e atual. São Paulo: Cortez, 2007.

SZEWCZYK, Sonia. Ensino de língua estrangeira: entraves e possibilidades. In: FILIPOUSKI, Ana M. R.; MARCHI, Diana M.; SCHAFFER, Neiva O. (Orgs.). Teorias e fazeres na escola em mudança. Porto Alegre: Editora da Ufrgs, 2005. p. 64-73. 